\author{
Eui-Jin Cho, \\ Se-Hoon Kim, \\ Won-Hyung Kim, \\ Sung-Won Jin, \\ Seung-Hwan Lee, \\ Bum-Joon Kim, \\ Sung-Gon $\mathrm{Ha}$, \\ Sang-Dae Kim, \\ Dong-Jun Lim
}

Department of Neurosurgery, Korea University Ansan Hospital, Korea University College of Medicine, Ansan, Korea

\section{Corresponding Author:}

Se-Hoon Kim

Department of Neurosurgery, Korea University Ansan Hospital, Korea University Medical Center, 123 Jeokgeum-ro, Danwon-gu, Ansan 15355, Korea

Tel: +82-31-412-5050

Fax: +82-31-412-5054

E-mail: sehoonkim.2016@gmail.com

Received: March 23, 2017

Revised: June 19, 2017

Accepted: June 20, 2017

Copyright (C) 2017 by The Korean Spinal Neurosurgery Society

This is an open access article distributed under the terms of the Creative Commons Attribution Non-Commercial License (http://creativecommons.org/licenses/bync/4.0/) which permits unrestricted noncommercial use, distribution, and reproduction in any medium, provided the original work is properly cited.

\title{
Clinical Results of Odontoid Fractures according to a Modified, Treatment-Oriented Classification
}

Objective: Odontoid fracture is common in cervical injury, representing about $20 \%$ of total cervical fractures. Classic odontoid fracture classification focused on anatomy of fracture site has no treatment recommendation and a modified treatment-oriented classification of odontoid fracture was suggested in 2005. We reviewed our odontoid fracture patients to assess the feasibility and efficacy of Grauer's classification.

Methods: Between October 2000 and September 2015, we collected data from patients who came to our institute for odontoid fracture. Demographic data of patients was reviewed, and neck visual analog scale (VAS) score and fusion rate were assessed by reviewing electronic medical records retrospectively.

Results: Sixty-nine patients out of a total of eighty two odontoid fracture patients were reviewed according to Grauer's classification. Neck VAS of all subtypes in odontoid fracture classification were decreased at last follow-up $(p=0.001)$. Overall fusion rate was $88.4 \%$ at last follow-up. Concordance rate between Grauer's recommendation and our treatment was $69.9 \%$, especially in type II with the concordance higher than $80 \%$. Complication was minimal representing $7.2 \%$, only in types I and III.

Conclusion: In this study, there were statistically significant improvement in all subtypes in terms of neck VAS at the last follow up, especially in types II and III. Grauer's classification appears to be meaningful to decide treatment plan for odontoid fractures, especially type II odontoid fracture.

Key Words: Odontoid fracture, Treatment, Classification

\section{INTRODUCTION}

In spinal injury population, over $60 \%$ is related in cervical injury ${ }^{12)}$. About $20 \%$ of cervical spine fractures are odontoid fractures ${ }^{10}$. In younger patients, these fractures are usually made by high-velocity accidents, whereas falls in elderly patients ${ }^{8)}$. There are variable treatment options from collar immobilization (including collar, halo-vest) to anterior screw fixation or posterior fusion. Anderson and D'Alonzo ${ }^{2)}$ proposed a classification of odontoid fractures and their classification has been still used till today. But classification of Anderson and D'Alonzo has no treatment guideline, and the treatments of odontoid fracture are controversial. In 2005, Grauer et al. ${ }^{8)}$ proposed a modified, treatment-oriented classification of odontoid fractures. This classification divided odontoid fractures into 3 groups, especially type II fractures into three subgroups (subclass A, B, and C). We reviewed odontoid fracture patients treated in our institute to assess the feasibility and efficacy of the Grauer's classification.

\section{MATERIALS AND METHODS}

\section{Patients}

Between October 2000 and September 2015, we reviewed patients who were diagnosed with odontoid fracture in Korea University Medical Center. We excluded any patients refused recommended treatments or, were transferred to other hospitals. We checked all patients regarding neck visual analogue scale (VAS) score at initial or preoperative and postoperative or final follow-up. Orthotopic, lateral, and open mouth X-rays, Occipitocervical computed tomography (CT) or 3-dimensional reconstruction CT (3DCT) were evaluated at pretreatment and posttreatment states in all patients. Cervical magnetic resonance imaging (MRI) was evaluated at pretreatment state in all patients, and for patients with spinal cord injury patients, follow-up cervical MRI was also performed at posttreatment state. More than 1-year follow-up was done in all patients and mean follow-up period was 25.52 months (range, 12-60 months). Simple 
\& dynamic cervical spine X-ray, 3D-CT follow-up for instability and fusion assessment were done at 1-year follow-up.

\section{External Fixation or Surgical Treatment}

In 30 patients, immobilization was performed with cervical Halter traction or skull traction for 2 weeks, and then Halovest for 3 months. Some patients who were not able to do Halovest, external immobilization was done with Philadelphia brace for the same duration.

Anterior cervical stabilization was done via anterior odontoid screw fixation using a odontoid screw in 21 patients. UCSS (Medtronic Inc., Minneapolis, MN, USA) anterior cannulated odontoid lag screw $3.5 \mathrm{~mm}$ in diameter was implanted in all cases. All patients wore Philadelphia brace for three months.

Posterior stabilization was done with $\mathrm{C} 1$ lateral mass $-\mathrm{C} 2$ pedicle screws in 18 patients. The $3.5-\mathrm{mm}$ diameter and $22-$ to 26-mm length atlanto-axial lateral mass/pedicle screws were placed at both intersection $2 \mathrm{~mm}$ above the lower edge of posterior arch and medial clination of 5-10 degree. All patients wore Philadelphia brace for 3 months.

\section{Statistics Analysis}

Statistical analysis was performed with SPSS ver. 13.0 (SPSS Inc., Chicago, IL, USA). A p-value of $<0.05$ was considered statistically significant. Paired Student t-test was used for comparing pre- and posttreatment VAS score.

\section{RESULTS}

We reviewed 82 odontoid fracture patients who came to our institute from October 2000 to September 2015. Thirteen patients were excluded due to refusal of treatment or transfer to other hospitals. Finally, 69 patients were reviewed according to

Table 1. The demographics of patients with odontoid fracture at presentation $(n=69)$

\begin{tabular}{lc}
\hline \hline Variable & Value \\
\hline Age (yr) & $49.8 \pm 19.6$ \\
Sex & 50 \\
$\quad$ Male & 19 \\
$\quad$ Female & \\
Trauma mechanism & 43 \\
$\quad$ Fall & 20 \\
Motor vehicle accident & 6 \\
Others & 11 \\
Additional cervical fracture & 2 \\
Associated spinal cord injury & $6.17 \pm 1.83$ \\
VAS score & $25.5 \pm 12.1$ \\
Follow-up period (mo) & \\
Values are presented as mean \pm standard deviation or number. \\
VAS, visual analog scale.
\end{tabular}

Grauer's classification and we compared our treatment with recommended treatment by Grauer's classification and reviewed efficacy of Grauer's classification.

Fifty male and nineteen female patients were reviewed. Average of patient age was 49.8 years old and standard deviation was 19.6 years. Most of the patients (43 patients, 62.3\%) were injured by fall down, 20 (29.0\%) by vehicle accident, 6 by others such as fighting and so on. 11 patients were found to have other cervical spine fracture in addition to odontoid fracture. Tow patients had cord injury and weakness, quadriplegia. Initial VAS pain score was $6.17 \pm 1.83$ (Table 1 ).

According to Grauer's classification, 3 patients were in type I fracture, 4 in type IIA, 16 in type IIB, 8 in type IIC, and 38 in type III. In type I, external immobilization is recommended treatment by Grauer's et al. ${ }^{8)}$. Concurrence of treatment in type I fracture was 1 patient of total 3 patients (33.33\%). One patient was treated with anterior odontoid screw fixation, the other was treated with posterior screw fixation. In type IIA, all were corresponded with recommend treatment of Grauer's classification, external immobilization. In type IIB, 13 of 16 patients (81.25\%) underwent anterior screw fixation, 2 treated with external fixation, and 1 was treated with posterior screw fixation, In type IIC, 7 of $8(87.5 \%)$ were treated with posterior screw fixation, the other with external immobilization. In type III, 23 of 38 $(60.5 \%)$ were treated with external immobilization, but 8 with anterior screw fixation, 7 with posterior screw fixation.

In all subtypes of odontoid fracture, VAS pain score was decreased after treatment $(\mathrm{p}<0.05$ in subtypes IIB, IIC, and III) (Table 2). Fusion rate was higher than $87 \%$ in all subgroups except type I (66.6\%) which might be because of small number

Table 2. Analysis of neck VAS according to Grauer's classification

\begin{tabular}{lccc}
\hline \hline Type & Pre VAS & Post VAS & p-value \\
\hline I $(n=3)$ & $4.67 \pm 2.87$ & $2.33 \pm 0.94$ & 0.180 \\
IIA $(n=4)$ & $7.25 \pm 0.83$ & $4.75 \pm 0.43$ & 0.062 \\
IIB $(n=16)$ & $6.50 \pm 2.03$ & $3.19 \pm 1.18$ & 0.001 \\
IIC $(n=8)$ & $6.25 \pm 1.48$ & $3.75 \pm 1.85$ & 0.016 \\
III $(n=38)$ & $6.03 \pm 1.68$ & $3.05 \pm 1.52$ & 0.001 \\
Total $(n=69)$ & $6.17 \pm 1.83$ & $4.70 \pm 1.51$ & 0.001 \\
\hline
\end{tabular}

Values are presented as mean \pm standard deviation.

VAS, visual analog scale; Pre, pretreatment; Post, posttreatment.

Table 3. Analysis of treatment results of 69 odontoid fractures according to Grauer's classification

\begin{tabular}{lccc}
\hline \hline Type & Concordance & Fusion rate & Complications \\
\hline I $(n=3)$ & $1(33.3)$ & $2(66.6)$ & $1(33.3)$ \\
IIA $(n=4)$ & $4(100)$ & $4(100)$ & $0(0)$ \\
IIB $(n=16)$ & $13(81.3)$ & $15(88.2)$ & $0(0)$ \\
IIC $(n=8)$ & $7(87.5)$ & $7(87.5)$ & $0(0)$ \\
III $(n=38)$ & $23(60.5)$ & $34(91.9)$ & $4(10.5)$ \\
Total $(n=69)$ & $48(69.9)$ & $61(88.4)$ & $5(7.2)$ \\
\hline
\end{tabular}


of patients. Complications such as uncontrolled pain, instability were found only in type I, III patients treated with external immobilization, not surgical treatment (Table 3). According to Grauer's classification, concurrence of actual treatment was highly related in type II fractures.

\section{DISCUSSION}

In traumatic cervical spinal injury, odontoid fracture is a common injury. There are several classifications of odontoid fractures. Schatzker's classification divided odontoid fracture into 2 groups; fracture at below and above attachment of accessory ligaments ${ }^{15)}$. Mourgue's classification proposed 2 groups as fracture at base (union rate 100\%) and neck (union rate less than $50 \%)^{6}$. Althoff's classification proposed 4 types of odontoid fractures; first type with fracture above the neck have a pseudoarthrosis rate about $64 \%$, second type fracture is through the neck and have pseudoarthrosis rate around 55\%, third type in which the fracture includes lateral mass have 50\% union rate, fourth type concerns fractures at body of vertebral axis and have high rate of union about $93 \%{ }^{1}$. Commonly applied odontoid fracture classification, Anderson and D'Alonzo classification, and Grauer's classification have no difference in types I and III. In types I and III odontoid fracture, fracture line was usually in cancellous bone, so healing rate of both fracture groups are relatively high ${ }^{5}$. Therefore, external immobilization (including traction, halo-vest fixation, brace immobilization, and so on) was used commonly in types I and III odontoid fractures. Type II odontoid fracture is on connection of odontoid and vertebral body, and it makes injury in blood vessel commonly ${ }^{7,16}$. It makes fracture healing poor, so external immobilization is not proper to treat type II odontoid fracture. So, Grauer et al. ${ }^{8)}$ suggested new classification in 2005, that distributed type II fracture to 3 subtypes, IIA, IIB, and IIC. Type IIA odontoid fracture is transverse fracture without comminution and displacement is less than $1 \mathrm{~mm}$. Type IIB is fracture that fracture line is anterosuperior to posteroinferior direction or displacement is over than $1 \mathrm{~mm}$. Type IIC is fracture that fracture line is anteroinferior to posterosuperior direction or has significant comminution (Fig. 1). Each types have different treatment recommendation as Table $4^{8)}$.

There is controversy about proper treatment in odontoid fractures $^{3)}$. We treated odontoid fracture patients (1 in type I, 4 in type IIA, and 23 in type III) with immobilization as Grauer's classification recommendation. In our cases, union rate is relatively higher (over than 85\%) although several papers have high nonunion rate $(13 \%-72 \%)$ with immobilization ${ }^{13,14)}$. Generally,

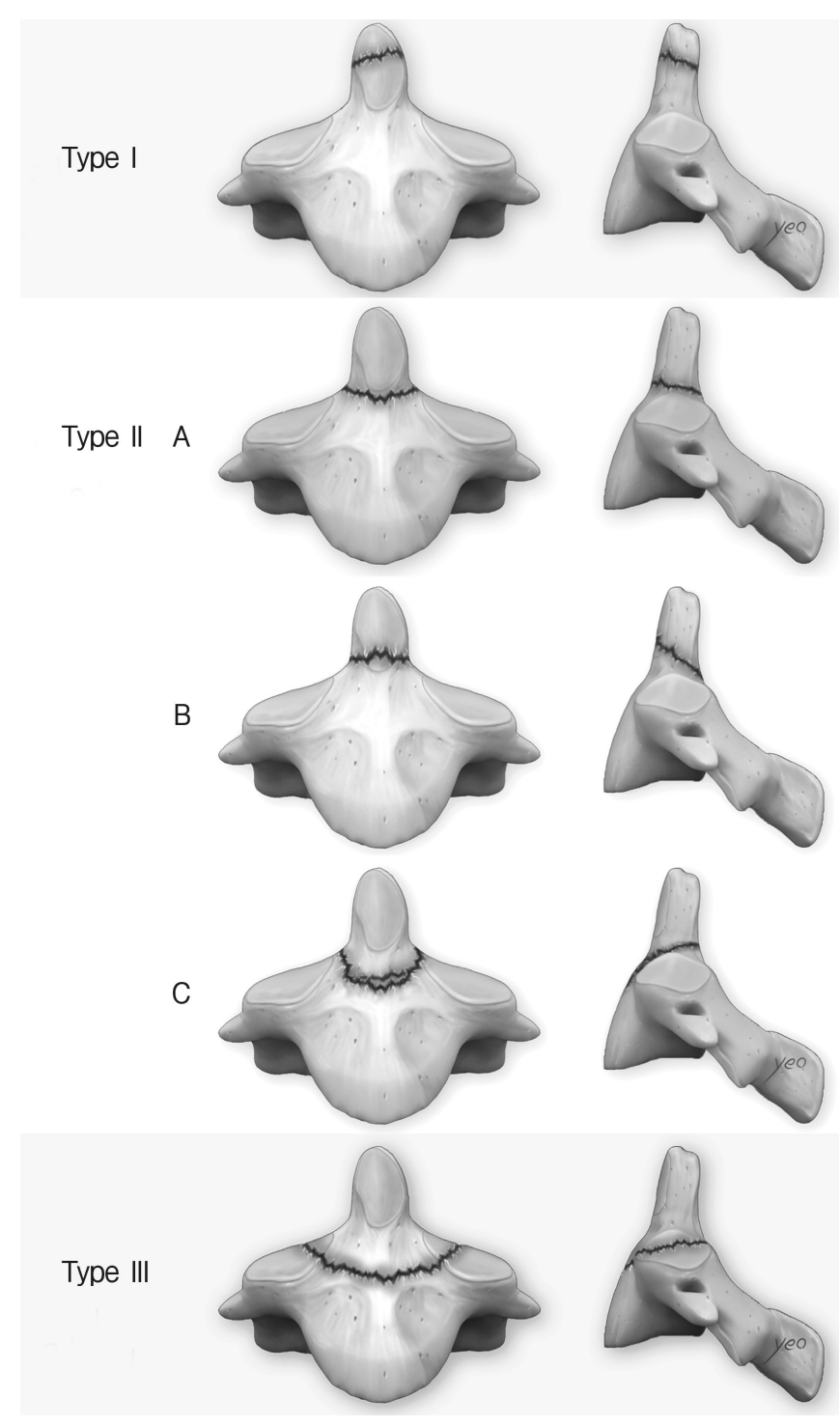

Fig. 1. Proposed subclassification of type II odontoid fracture by Grauer et al. ${ }^{8)}$.

Table 4. Proposed classification and treatment algorithm of Odontoid fractures by Grauer et al. ${ }^{8)}$

\begin{tabular}{lll}
\hline \hline Subtype & Description & Treatment guideline \\
\hline Type I & Above inferior aspect of C1 anterior arch & External immobilization* \\
Type II & Between types I and II fractures & External immobilization \\
Type IIA & Nondisplaced fracture & Anterior screw fixation \\
Type IIB & Anterior superior to posterior inferior and displaced transverse fractures & Posterior atlantoaxial fusion \\
Type IIC & Anterior inferior to posterior superior or comminuted fractures & External immobilization \\
Type III & Including at least one of the superior articular facets of C2 & \\
\hline
\end{tabular}

\footnotetext{
"Halo-vest fixation or Philadelphia brace.
} 
external immobilization is contraindicated because of low bone density, decreased blood supply, etc. ${ }^{7}$. So, we treated old age patients by anterior or posterior screw fixation although they are in type I, III odontoid fracture. Complication such as uncontrolled neck pain, instability was seen in several cases, but overall complication rate was low. We can consider external immobilization as primary treatment in type I, III patients without any contraindications.

Anterior odontoid screw fixation has clinical effect about high fusion rate and preservation of cervical rotation". Thirteen patients of type IIB, some patients in other types were treated with anterior odontoid screw fixation (Fig. 2). There was no complication such as pain aggravation, displacement and so on. All 13 patients treated with anterior odontoid screw in type IIB fracture were recovered with bone union. Eight patients in type III fracture were also treated with anterior screw fixation. There was no complication and successful recovery in almost patients. All patients who were treated with anterior odontoid screw fixation
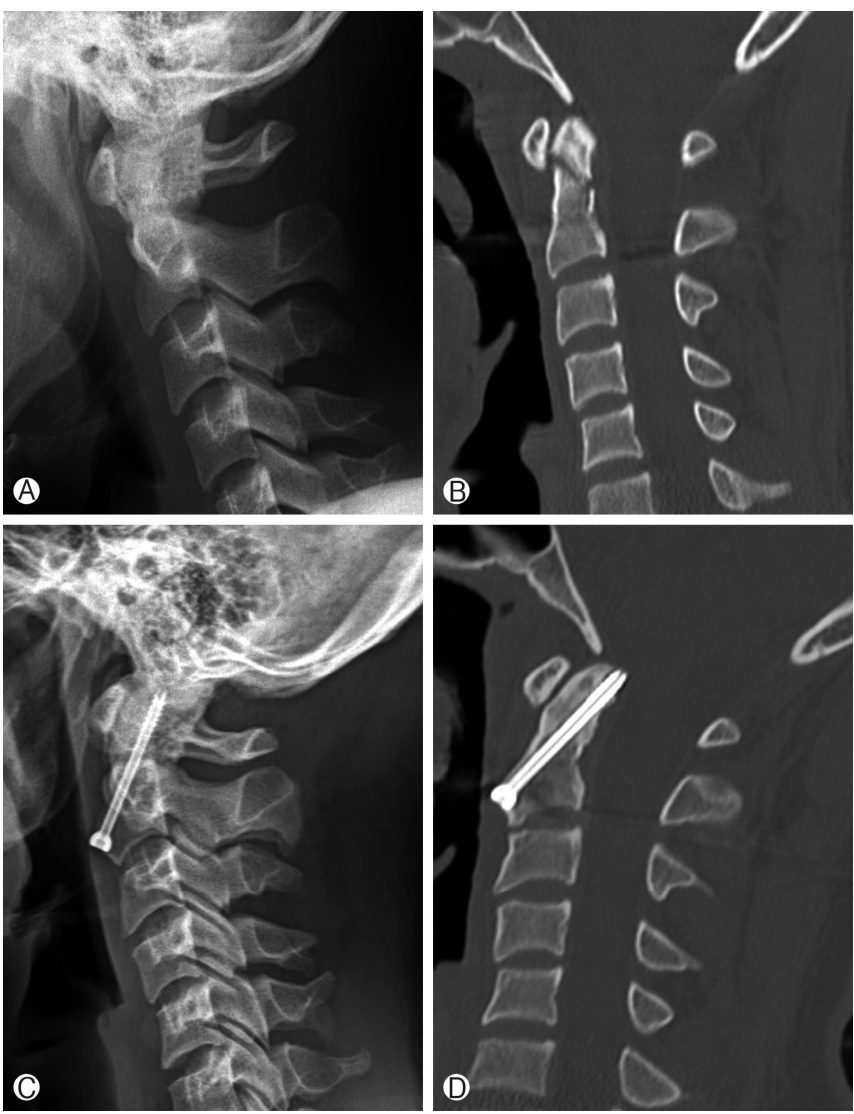

Fig. 2. An illustrative case of type IIB patient treated by anterior odontoid screw fixation. A 15 -year-old male patient had odontoid fracture, type IIB by Grauer's classification from a vehicle accident trauma. Initial X-ray (A) and CT (B) were evaluated. Anterior screw fixation was done and follow-up X-ray (C) and CT (D) were evaluated at postoperative 12 months, which demonstrated bone union at the fracture site. had no or minimal limitation of neck rotation. As this result, anterior screw fixation can be a good treatment option in type IIB odontoid fracture if operation is available and avoid excessive neck exercise after operation.

Posterior atlanto-axial pedicle screw fixation and wiring were considered as preferred treatment options in type II odontoid fractures, previously ${ }^{4,11)}$. It was done in 7 patients with type IIC. Some patients who had severe displacement, were not profit to Halo-vest fixation were also treated with posterior screw fixation. Bone union rate was high $(87.5 \%$ in type IIC) and complication rate was very low (only 1 case in type III, broken screw by secondary trauma). All patients suffered from limitation of neck rotation. Over all fusion rate was higher than $90 \%$ in cases of posterior atlanto-axial screw fixation. Posterior atlanto-axial screw fixation can be a good option for type III or severe displacement odontoid fracture patients. In cases of difficult placement of $\mathrm{C} 2$ pedicle screw from narrow pedicle or high-riding vertebral
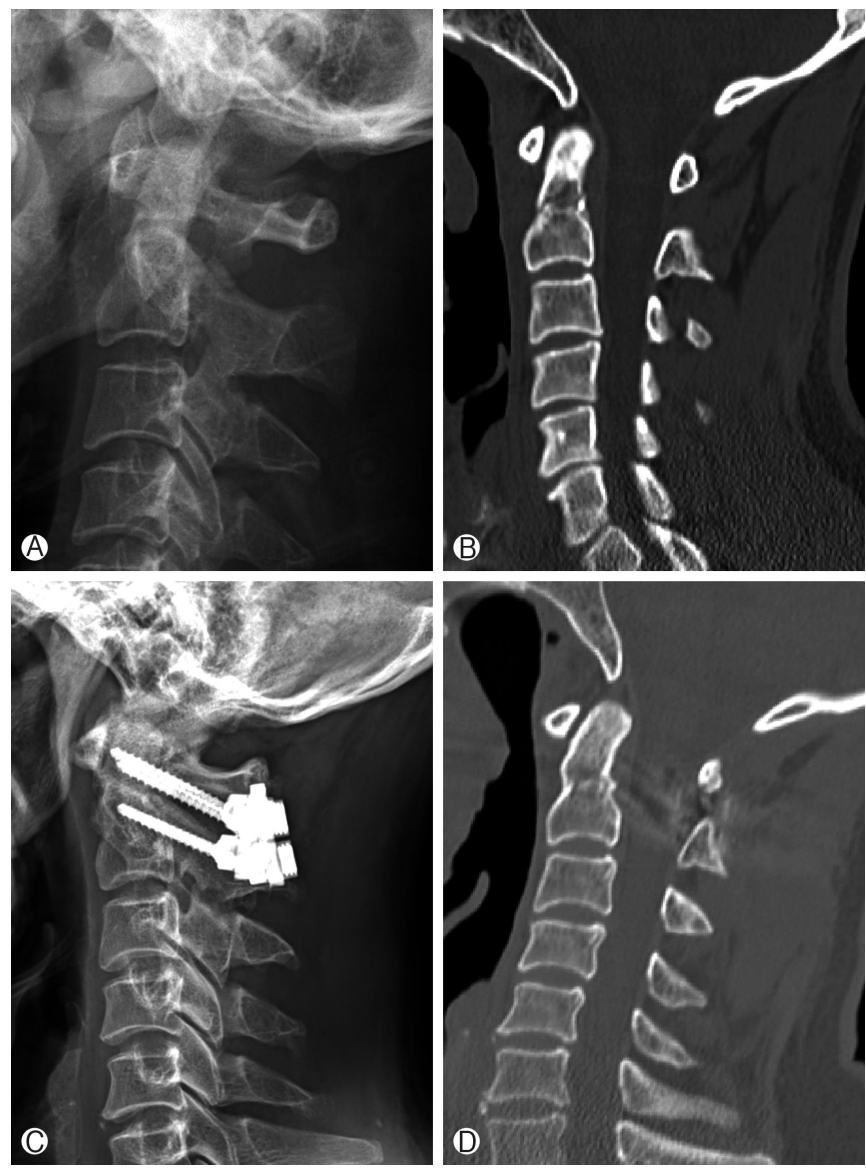

Fig. 3. An illustrative case of type IIC patient treated by posterior atlanto-axial translaminar screw fixation. A 40-year-old male patient was diagnosed of odontoid fracture, type IIC by Grauer's classification from a fall down trauma. Initial X-ray (A) and CT (B) were evaluated. Posterior screw fixation was done at C1 lateral mass and $\mathrm{C} 2$ pedilcle and follow-up X-ray (C) and CT (D) were evaluated at postoperative 12 months. 
Table 5. Analysis of treatment discordance cases with Grauer's classification

\begin{tabular}{|c|c|c|c|}
\hline Sex/age (yr) & Recommendation (type) & Treatment & Reasons \\
\hline $\mathrm{M} / 60$ & Immobilization (I) & Posterior fixation & Lamina fracture \\
\hline $\mathrm{M} / 66$ & Immobilization (I) & Posterior fixation & Lamina fracture \\
\hline $\mathrm{M} / 74$ & Anterior fixation (IIb) & Posterior fixation & Pedicle fracture \\
\hline $\mathrm{F} / 91$ & Anterior fixation (IIb) & External immobilization & Poor general condition \\
\hline $\mathrm{F} / 51$ & Anterior fixation (IIb) & Posterior fixation & Lamina fracture \\
\hline $\mathrm{F} / 54$ & Posterior fixation (IIc) & External immobilization & Poor general condition \\
\hline $\mathrm{M} / 13$ & External immobilization (III) & Anterior fixation & Dislocation \\
\hline $\mathrm{M} / 41$ & External immobilization (III) & Posterior fixation & Lamina fracture \\
\hline $\mathrm{M} / 32$ & External immobilization (III) & Posterior fixation & Pedicle fracture \\
\hline $\mathrm{F} / 64$ & External immobilization (III) & Anterior fixation & Low BMD* \\
\hline $\mathrm{F} / 47$ & External immobilization (III) & Anterior fixation & Low BMD* \\
\hline $\mathrm{F} / 59$ & External immobilization (III) & Anterior fixation & Low BMD* \\
\hline $\mathrm{F} / 64$ & External immobilization (III) & Anterior fixation & Low BMD* \\
\hline $\mathrm{F} / 74$ & External immobilization (III) & Anterior fixation & Low BMD* \\
\hline $\mathrm{M} / 77$ & External immobilization (III) & Posterior fixation & Lamina fracture \\
\hline $\mathrm{M} / 42$ & External immobilization (III) & Posterior fixation & Pedicle fracture \\
\hline $\mathrm{M} / 52$ & External immobilization (III) & Posterior fixation & Pedicle fracture \\
\hline $\mathrm{F} / 51$ & External immobilization (III) & Anterior fixation & Low BMD* \\
\hline $\mathrm{M} / 43$ & External immobilization (III) & Posterior fixation & Lamina fracture \\
\hline $\mathrm{F} / 62$ & External immobilization (III) & Anterior fixation & Low BMD* \\
\hline $\mathrm{M} / 54$ & External immobilization (III) & Posterior fixation & Pedicle fracture \\
\hline
\end{tabular}

$\mathrm{BMD}$, bone marrow density.

"Low BMD means lower than -2.5.

artery, C2 translaminar screw fixation can be safely performed (Fig. 3).

There were some cases that were discordant with treatment recommendation of Grauer's classification. When we decided treatment plan, we considered patients condition, instability, bone marrow density. So, we did other treatments in 21 patients, that anterior or posterior fixation in types I and III, posterior fixation or external immobilization in type Ilb, external immobilization in type III as Table 5.

There are some limitations in this study such as small sample size, short-term period, retrospective study, only single center study. It needs to study in larger sample size with multicenter study, long-term follow-up, prospective study.

\section{CONCLUSION}

Odontoid fractures could be treated with various procedures including external immobilization, anterior screw fixation, posterior atlanto-axial fusion. Although other factor such as instability, bone density and patients conditions are important, type of odontoid fracture seems to be the most important factor that decides treatment plan in odontoid fracture patients. As followed Grauer's classification, types I, IIA, III of odontoid fracture is treated with external immobilization using Halo-vest fixation or Philadelphia brace. Anterior screw fixation in type IIB, posterior atlanto-axial fusion in type IIC are usually recom- mended for treatment.

We refer the proposed treatment-oriented classification by Grauer et al..$^{8)}$ is recommendable when making a treatment plan in odontoid fracture patients.

\section{CONFLICT OF INTEREST}

No potential conflict of interest relevant to this article was reported.

\section{ACKNOWLEDGMENTS}

The authors would like to thank medical illustrator, Sangwon Yeo, for his help with the illustrations.

\section{REFERENCES}

1. Althoff B: Fracture of the odontoid process. An experimental and clinical study. Acta Orthop Scand Suppl 177:1-95, 1979

2. Anderson LD, D'Alonzo RT: Fractures of the odontoid process of the axis. J Bone Joint Surg Am 56:1663-1674, 1974

3. Bransford RJ, Alton TB, Patel AR, Bellabarba C: Upper cervical spine trauma. J Am Acad Orthop Surg 22:718-729, 2014

4. Brooks AL, Jenkins EB: Atlanto-axial arthrodesis by the wedge compression method. J Bone Joint Surg Am 60:279-284, 1978

5. Chen Q, Liu WM, Wang HR, Jiang LB, Xing R, Dong J: Efficacy 
and safety of different treatments for Grauer type II odontoid fractures: a preliminary study. Int J Clin Exp Med 9:8145-8152, 2016

6. de Mourgues GM, Fisher L, Schnepp J, Comtet J, Vidalain JP: Fractures de I'omoplate. A propos d'une serie de 130 cas traitts orthoptdiquemen. Soc Chir Lyon 8:47-50, 1972

7. Govender S, Maharaj JF, Haffajee MR: Fractures of the odontoid process. J Bone Joint Surg Br 82:1143-1147, 2000

8. Grauer JN, Shafi B, Hilibrand AS, Harrop JS, Kwon BK, Beiner $\mathrm{JM}$, et al: Proposal of a modified, treatment-oriented classification of odontoid fractures. Spine J 5:123-129, 2005

9. Lee DS: Anterior screw fixation of anteriorly displaced type III odontoid fracture corrected by transoral digital manipulation. Korean J Spine 10:101-103, 2013

10. Maak TG, Grauer JN: The contemporary treatment of odontoid injuries. Spine (Phila Pa 1976) 31(11 Suppl):S53-60, 2006

11. Magerl F, Seemann PS: Stable posterior fusion of the atlas and axis by transarticular screw fixation, in Kehr P, Weidner A (eds).
Cervical spine I, Strasbourg 1985. Wien: Springer-Verlag, pp322327, 1987

12. Ochoa G: Surgical management of odontoid fractures. Injury 36 Suppl 2:B54-64, 2005

13. Patel A, Zakaria R, Al-Mahfoudh R, Clark S, Barrett C, Sarsam $\mathrm{Z}$, et al: Conservative management of type II and III odontoid fractures in the elderly at a regional spine centre: a prospective and retrospective cohort study. Br J Neurosurg 29:249-253, 2015

14. Pepin JW, Bourne RB, Hawkins RJ: Odontoid fractures, with special reference to the elderly patient. Clin Orthop Relat Res (193): 178-183, 1985

15. Schatzker J, Rorabeck CH, Waddell JP: Fractures of the dens (odontoid process). An analysis of thirty-seven cases. J Bone Joint Surg Br 53:392-405, 1971

16. Schiff DC, Parke WW: The arterial supply of the odontoid process. J Bone Joint Surg Am 55:1450-1456, 1973 